\title{
Bridging the Gap: \\ Music Business Education and the Music Industries
}

\author{
Andrew Dyce and Richard Smernicki \\ University of the Highlands and Islands, Perth College, Scotland \\ This paper was presented at the 2018 International Summit of the \\ Music \& Entertainment Industry Educators Association \\ March 22-24, 2018
}

https://doi.org/10.25101/18.20

\section{Abstract}

This research analyses the key challenges in developing a contemporary music industry project as part of music business educational programs based in the U.K. It will identify the key challenges of understanding and implementing industry related projects into educational programs. This includes the analysis of the outcomes of these projects and the employability benefits they provide to students. The research will be presented in two sections, the first of which includes an analysis of current research and policies from government/industry bodies. The second focuses on how educational institutions engage with the music industries to ensure the relevancy of their projects and programs. The research will offer insight into six U.K. higher education institutions. This provides a snapshot of current issues including access, experiential education, and employability. Our research used qualitative interviews with faculty and students. The findings demonstrate a range of challenges and opportunities that are evident throughout music business programs and cultural policy, highlighting the issues in bridging the gap between education and employment. Specifically, this report focuses on the growing discipline of music business as a distinct field of study and the designed outcomes of educational programs in this area.

Keywords: music business, music industry, education, employment, experiential learning, project-based learning, internships, best practices.

\section{Introduction}

Music business educators are motivated to provide the music industry with skilled individuals to meet the demands of employers. To do this effectively and to bridge the gap between education and employment it is crucial to analyze the value of experiential learning projects embedded within educational programs while also understanding key research/policies impacting music industry education. Typically, these learning projects, in our experience, have been focused towards record label or recorded music related activities. Global recorded music industry revenues are growing once again with recent figures published (IFPI 2018) showing an increase of $8.1 \%$. This is the third consecutive year of growth after fifteen years of declining income driven by a $41.1 \%$ growth in streaming revenue. This global trend of growth is reflected throughout the U.K. music market. Measuring Music Report (UK Music 2017) figures show total gross value added (GVA) of $£ 4.4$ billion, an increase of $6 \%$. Total export revenue generated by the U.K. music industry in 2016 was $£ 2.5$ billion up $13 \%$, total live music audience in the U.K. in 2016 was 30.9 million a $12 \%$ increase from 2015. In 2016 total U.K. employment sustained by music was 142,208 , an increase of $19 \%$ from the previous year. These statistics illustrate a positive outlook for the future of the music industry, hence we must ensure music business education is suited to meet changing industry dynamics.

\section{Aims of Research}

While developing this research, it became clear that our findings may be useful to a wider audience than institutions we currently work with. Music business as an academic discipline continues to grow globally and, as a result, our findings may be of some value to new providers of music business education. During this process we decided to focus our efforts on identifying best practice in music business education in the U.K. What does best practice look like and how do institutions measure this? In this process we identified four key themes: 
1. Skills Gap - the perceived gap between current students and skills required by employers

2. Skills Clusters - identifying skills that can be grouped or categorized to form a clearer understanding

3. Experiential Learning - value is placed on practical music industry experience

4. Assessed/Non-assessed projects - differences in student engagement between assessed/non-assessed projects

This focus provided the foundation for our research while ensuring that our findings would have a practical output, which could inform existing music business education in any institution.

\section{Methodology and Research Design}

Our methodology consisted of gathering qualitative data through semi-structured interviews with faculty and students from six U.K. higher education institutions delivering music business programs. We selected these institutions for data collection as those in England are fee paying whereas Scottish universities and colleges are non-fee paying, this is discussed further when we examine limitations of our research. Listed are the six institutions we used as a basis for data gathering:

1. University of the Highlands \& Islands, Scotland

2. Edinburgh College, Scotland

3. Glasgow Kelvin College, Scotland

4. New College Lanarkshire, Scotland

5. Bucks New University, England

6. University of West London, England

Our approach was to interview six music business lecturers. These semi-structured interviews allowed the respondent to openly discuss areas of best practice in relation to experiential learning. Interviewing provided highly personalized data from each respondent while also allowing for probing discussions. It has been argued that adopting semi-structured interviews with interviewees (academic staff) provides freer and in-depth responses for analysis (Mason 2018). Interviews were conducted over a four-week period and lasted around thirty minutes. Due to the geographical spread of our interviewees telephone interviews were the most efficient approach.

Data gathering from students was achieved using a fixed set of questions sent by email thus allowing us to gather responses from a large number of respondents. Although this approach did limit our ability to probe responses, it did allow for identification of common themes enabling deep analysis of a large subject group. Data was gathered from twenty-five students studying at higher education institutions in Scotland and England.
In the next section, we outline the existing research used to inform this paper and this presents another limitation due to the lack of research specific to music business education. Most available sources, especially within the U.K., tend to focus more on music performance education. However, organizations such as MEIEA are helping minimize this issue.

\section{Literature Review}

To further understand the focus of our research, we engaged with a range of existing research and ongoing discussions relevant to developing student skills. During this process, the lack of research specific to music business education became apparent. To mitigate this, our approach considered similar or related educational programs and practices consistent within the creative industries in broad terms. This included an analysis of research related to project-based learning, work experience/internships and handson learning.

In 2012 ArtQuest produced a review titled Intern Culture (Hope and Figiel 2012) of established practices relating to internships and the legalities, from most perspectives, of current discussion in this area. While this review focused on internships in the visual arts, there were notable similarities within their examples and with students seeking employment in the music industry. This review offered a foundation for our research project while highlighting some of the ethical conflicts that emerge when discussing the value of labor in the creative industries. Similarly, there has been further analysis of the concerns of unpaid work experience and the longer-term impacts this has on the creative industries (Siebert and Wilson 2013). Furthermore (Hesmondhalgh 2013) there is an argument that the system of work experience/internships has become the most apparent example of free labor in the creative industries. While our own research doesn't intend to explore the ethical considerations of these practices, which is commonplace in most creative industries, this remains a concern for students and educational institutions alike.

The Creative Industries Strategy (Creative Industries Council 2014) demonstrated a broad strategy to ensure a coherent approach from all parties in the creative industries. The strategy also contemplated the role of the government to support the creative industries, recommending an increase in support for industry training while improving links between educational bodies and employers. The study Learning Through Work Placements and Beyond (Little and Harvey 2006) identified that work-based learning required a skills development approach from both the employer and student. This also considered the importance of establishing the educational and practical development aims in each scenario. From a Scottish perspective, the Music Industry Scoping Report (Scottish Qualifications Authority 2017) 
has influenced our research. At the time of writing, this has yet to be published but it provided a survey of graduate skills and what industry demands of new music business graduates. Through this, some themes emerged including how highly employers value communication skills in new graduates. Generally, however, this report recommended more opportunities for graduates to learn by doing and less emphasis on solely academic work.

The balance between academic and practical work has long been a concern in higher education (Silver and Brennan 1988) and is a regular concern for music industry educators. A study (Tribe and Kemp 1999) conducted in the U.K. while music industry programs were in their infancy, identified that an $80 / 20$ split in favor of theoretical work over practical was common but required further research. To date, there appears to be little evidence of consensus on the balance that music industry programs should achieve. The issue of balance is central to any debate on equipping students for a career in the music industry.

In the U.K., the trade body UK Music has attempted to position itself between education and the music industry. One study (Bennett 2015) guided by UK Music examined the perceptions of employers on music industry education. Naturally, these ranged from generally supportive to an aversion to music programs. The most common explanation for this range of opinions, in this study, appears to be focused on levels of practical and theoretical work with employers favoring the former and universities favoring the latter. A study in Germany (Wickström, Lücke, and Jóri 2015) also discusses the importance of practical learning for both music and music business programs.

A fellow MEIEA member, David Kopplin, conducted perhaps the most valuable research available to our project. His work Best Practices in Music Industry Education (Kopplin 2016) provided a U.S. perspective of hands-on learning and the value of internships. This research proved to be especially helpful to our own understanding, as it had considered several areas which we previously had not. This included the level of support from each institution and the various methods of tracking graduate activities as they progress through their careers.

\section{Findings}

Many key themes emerged through analysis of the data collected from learners and lecturers. These findings can be categorized into four areas:

\section{Skills Gap}

Students demonstrate an awareness of a skills gap and appreciate the value of experiential learning in the context of music industry "real world" projects. An understanding of how practical experience gained during study can increase an individual's employment options was also identified.

\section{'I've learned so much about myself and how to improve areas of weakness' (Interviewee 2)}

'Skills and experiences I have gained while working at the label have already helped me gain employment in the music industry' (Interviewee 1)

\section{Skills Clusters}

Identification of skills clusters were prevalent in our interviews. Skills clusters were presented in two categories, behavioral and technical. The majority of respondents cited the growth of communication techniques as an area of skills development. Establishing and maintaining professional networks was also highly rated by learners as an important area of skills development.

\section{'Developing communications skills and the value of networking' (Interviewee 4)}

\section{'Marketing skills are particularly easy to transfer' (Interviewee 5)}

\section{Experiential Learning}

The value of students gaining practical experience to music industry employers was identified as highly desirable for bridging the gap from study to employment. Published data was limited regarding graduate employment from each educational institution in our study, this suggests institutions adopt a more structured approach to music business graduate employment outcomes.

'We have had students go onto employment with Sony UK and Universal and "learning by doing" more has really helped build the students' confidence and develop "soft skills" such as those required to deal with real artists etc.'

(Interviewee 6)

\section{'We've had students get placements at theatres, at promoters, and marketing agencies because the skills they develop with us become transferable and that has real value' (Interviewee 3)}

\section{Non-Assessed Projects}

We asked lecturers if practical learning projects were embedded within modules and assessed. Although this is happening, the evidence suggests that educators and students value the flexibility of non-assessed projects.

'Staff and students tend to prefer non-assessed projects which are more flexible and often easier 
to adapt to match skills employers require' (Interviewee 6)

'This type of project allows students to learn practical skills out-with the usual constraints of academic study' (Interviewee 4)

\section{Conclusion}

While our research will continue and widen in the coming year, we are able to form three main conclusions based on our findings and discuss how these could provide valuable considerations for music business educators. The first conclusion we can draw is the preference of educators and students of non-assessed project learning, which can include employer-led internships or institution led projects. Students and educators appeared to prefer the flexibility of non-assessed project learning which could be adapted at any point to meet a realistic music industry scenario. Educators interviewed indicated that unlike assessed work, students had more opportunity to ensure the relevancy of their learning for a specific task or employer.

Our findings have also emphasized the aims of project learning and the varying perspectives that institutions have. The majority of our interviewees believed that this form of learning was employment- or skills-driven. In some instances, these aims were quite rigid and specific to an identified job specification. However, others adopted a more fluid approach, which allowed the learning aims to change throughout the project. Our findings also highlighted the awareness of skills gaps and clusters which students could address through these projects.

Despite all faculty interviewees adopting different methods of tracking graduates, there was widespread dissatisfaction with how effective these methods were. While some institutions believed tracking graduates was not their responsibility, others took almost complete responsibility for this, including administration and organizing alumni events. Our findings then indicate the need for a rethink of how we as educators understand the development of our graduates' careers and how we monitor them. We can conclude, from the institutions analyzed, that the most pro-active methods from all institutions are by far the most effective in this area. This suggests that unless there is a combination of methods and people involved in this process, including teaching, management, and administrative staff, understanding our graduates' career paths will prove to be elusive.

\section{Limitations}

Although our research is still being developed at the time of writing, this paper has some clear limitations which would reduce the impact our findings may have. It is important to identify what these limitations are and how these have impacted our work in a broad sense. Our research includes findings from six U.K. higher education institutions. While we believe this provides a useful snapshot of music business education in the U.K., it would be wrong to suggest this represents a complete overview of institutions delivering similar programs. It is also worth highlighting the key limitations when comparing educational institutions within the U.K. There are notable differences between Scotland, with no student tuition fees, and England, with tuition fees on average at $\$ 10,000$ per year.

Despite these limitations, we believe that further development of our research including more analysis of U.S. and European institutions will minimize the longer-term impact these limitations may have.

\section{Further Developments}

The development of our research will focus on collaborating with institutions in the U.S., Europe, and China. The purpose of this is to provide a broader range of current music business education and demonstrate a deeper understanding of how music business graduate skills are being developed globally. As previously mentioned, we will examine in greater detail methods for monitoring graduates and explore which strategies provide the most beneficial results for both educators and graduates. In collaboration with partners, we anticipate that this research will be developed into an educational toolkit for new and existing music business education providers.

\section{References}

Bennett, Toby. Learning the Music Business. London: King's College, 2015.

Creative Industries Council. Creative Industries Strategy. London: Creative Industries Council, 2014.

Hesmondhalgh, David. "User-Generated Content, Free Labour and the Cultural Industries." Ephemera: Theory and Politics in Organization 10, no. $3 / 4$ (2010): 267-284.

Hope, Sophie, and Joanna Figiel. Intern Culture: A literature review of internship reports, guidelines and toolkits from 2009-2011. London: ArtQuest, 2012. https:// www.artquest.org.uk/wp-content/uploads/Intern-Culture-report.pdf.

IFPI. Global Music Report 2018: Annual State of the Industry. London: IFPI, 2018. http://www.ifpi.org/downloads/GMR2018.pdf.

Kopplin, David. "Best Practices in Music Industry Education." Journal of the Music and Entertainment Industry Educators Association 16, no. 1 (2016): 73-96. https:// doi.org/10.25101/16.3.

Little, Brenda, and Lee Harvey. Learning Through Work Placements and Beyond. Sheffield: HECSU, 2006. 
http://www.hecsu.ac.uk/assets/assets/documents/

Learning through_work placements_and beyond.pdf.

Mason, Jennifer. Qualitative Researching. London: Sage, 2018.

Siebert, Sabina, and Fiona Wilson. All Work and No Pay: Consequences of Unpaid Work in the Creative Industries. Glasgow: University of Glasgow/Sage, 2013. https://doi.org/10.1177/0950017012474708.

Silver, Harold, and John Brennan. A Liberal Vocationalism. London: Routledge, 1988.

SQA. Music Industry Scoping Report. Edinburgh: Scottish Qualifications Authority, 2018.

Tribe, John, and Chris Kemp. "Music Industry Management Degrees: Hitting the Right Note?" Journal of Vocational Education and Training 51, no. 4 (1999): 521-36. https://doi.org/10.1080/13636829900200105.

UK Music. Measuring Music 2017. London: UK Music, 2017. https://www.ukmusic.org/assets/general/Measuring_Music_2017_Final.pdf.

Wickström, David-Emil, Martin Lücke, Martin and Anita Jóri. "Not without music business. The higher education of musicians and music industry workers in Germany." International Journal of Music Business Research 4, no. 1 (2015): 55-88.

Andrew Dyce has experience working in live music promotion and management in Scotland for the last twenty years. Currently Andrew co-runs Perth Music Expo conference and co-directs Vadana Records in Scotland. Alongside this, Andrew is the Program Leader of Music Business at the University of the Highlands and Islands. Andrew graduated from Birmingham City University with a post-graduate Master of Arts in Creative Industries and Cultural Policy with commendation. He had previously studied at the University of the West of Scotland, graduating a Bachelor of Arts in Commercial Music Marketing. His current research interests include music industries education and employment, youth music, and cultural policy in the U.K. Andrew has presented research at the University of Murcia (Spain), Istanbul Technical University (Turkey), and the Musicians' Union conference in Glasgow (Scotland). https://www.perth.uhi. ac.uk/subject-areas/music-and-music-business/ staff/andrew-dyce/

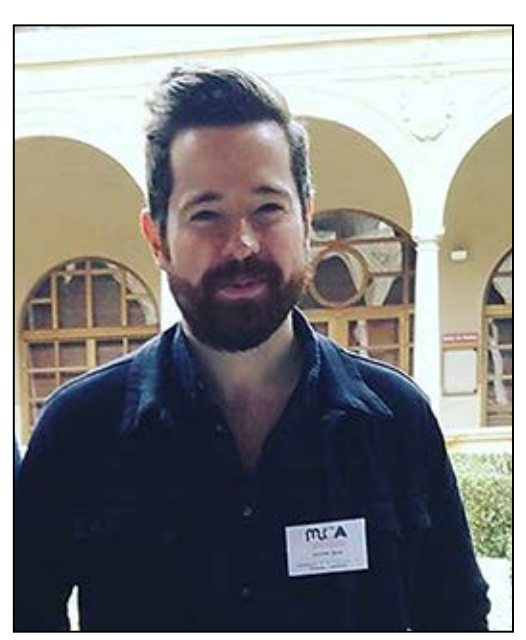

Richard Smernicki graduated from The University of Dundee Scotland achieving a Master of Arts Degree with Honors. After graduating he focused on a music performance career specializing in percussion while also working as a touring technician. In 2000 Richard started work as an A\&R representative for Universal Music UK where he was pivotal in signing Snow Patrol before taking up a similar role at Warner Bros. Records UK. Currently Richard is a Music \& Music Business lecturer at The University of the Highlands \& Islands, Perth College Scotland, delivering the Music Industry Schemed Degree, B.A. Hons. Richard teaches modules including Touring and Digital Music Industries, he also co-directs Vadana Records, the university's record label where students gain real world music industry experience. This inspired his current research 'Bridging the Gap' which analyzes how educational institutions engage with music industries to ensure the relevancy of their programs. In 2017 The National Student Survey ranked The University of the Highlands \& Islands, Perth College as the number one institution in the U.K. to study Music Business. https://www.perth.uhi. ac.uk/subject-areas/ music-and-music-business/staff/rik-smernicki

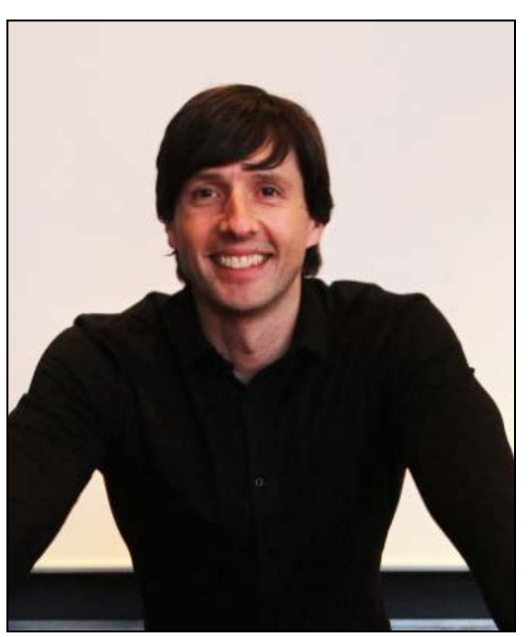




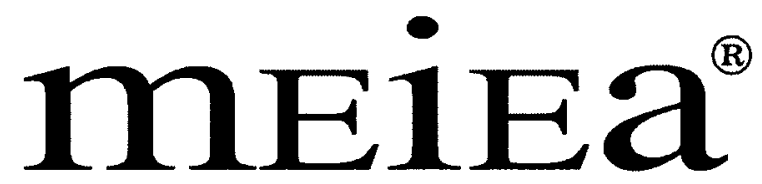

MUSIC \& ENTERTAINMENT INDUSTRY

EDUCATORS ASSOCIATION

\section{PROCEEDINGS OF THE \\ 2018 INTERNATIONAL SUMMIT}

OF THE

\section{MUSIC \& ENTERTAINMENT INDUSTRY EDUCATORS \\ ASSOCIATION}
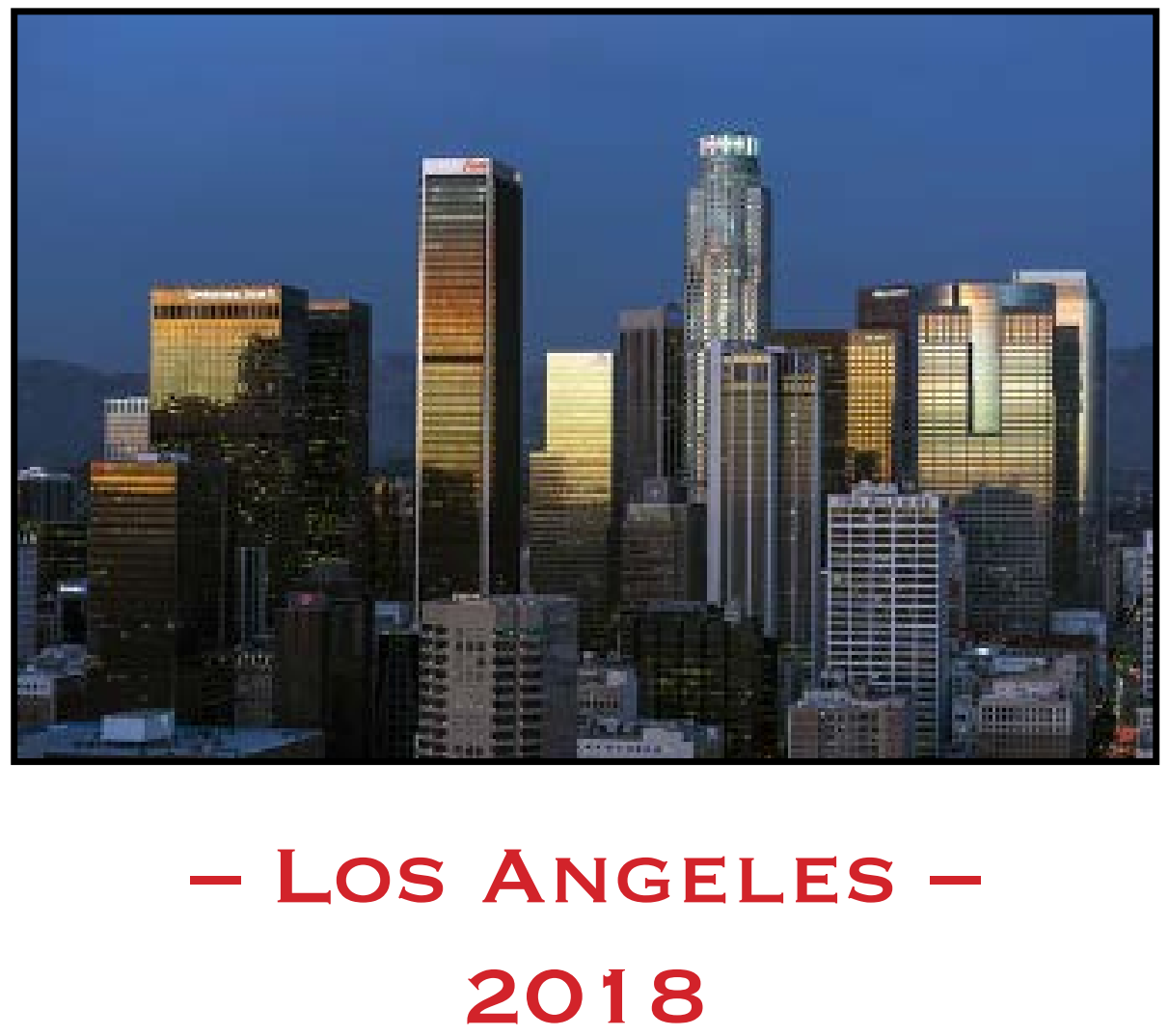

March 22 - 24, $2018 \cdot$ Embassy Suites by Hilton - Los Angeles/Glendale 